Lagasse, Peter F.; Spitz, William J.; Zevenbergen, Lyle W. A Methodology for Predicting Channel Migration NCHRP Project No. 24-16

Verfügbar unter / Available at:

https://hdl.handle.net/20.500.11970/100403

Vorgeschlagene Zitierweise / Suggested citation:

Lagasse, Peter F.; Spitz, William J.; Zevenbergen, Lyle W. (2002): A Methodology for Predicting Channel Migration NCHRP Project No. 24-16. In: Chen, Hamn-Ching; Briaud, Jean-Louis (Hg.): First International Conference on Scour of Foundations. November 17-20, 2002, College Station, USA. College Station, Texas: Texas Transportation Inst., Publications Dept.. S. 1051-1060. 


\title{
A Methodology for Predicting Channel Migration NCHRP Project No. 24-16
}

\author{
Peter Lagasse $^{(1)}$, William Spitz ${ }^{(2)}$, and Lyle Zevenbergen ${ }^{(3)}$ \\ (1) Senior Vice President, Ayres Associates, Fort Collins, CO 80527; PH (970) 223-5556 \\ ${ }^{(2)}$ Geomorphologist, Ayres Associates, Fort Collins, CO 80527; PH (970) 223-5556 \\ ${ }^{(3)}$ Project Manager, Ayres Associates, Fort Collins, CO 80527; PH (970) 223-5556
}

\begin{abstract}
Stream channel migration can have a significant impact on the design, maintenance, and inspection of bridges and other highway facilities. Practicing highway hydraulic engineers could benefit from a practical methodology to predict the rate and extent of channel migration in their efforts to reduce the cost of design, repair, rehabilitation, and countermeasures for lateral channel instability. The objective of Research Project 24-16 is to develop a practical methodology to predict the rate and extent of channel migration (i.e., lateral channel shift and down valley migration) near transportation facilities.

The research products will include not only a final report describing the predictive methodology, but also an extensive archived database, published on CD-ROM, that contains detailed morphological data, aerial photos, historical banklines, and maps for more than 1,400 bends on 87 rivers and streams across the United States. In addition, a stand-alone aerial photo/map comparison handbook that provides a complete applications supplement for Project 24-16 will be published. The comparison techniques in the handbook will include GIS measurements and extrapolation routines. The archived database and handbook will be intended for use by FHWA and State DOTs, but should also be of interest to future researchers and practitioners responsible for river channel maintenance and river restoration/rehabilitation projects.
\end{abstract}

\section{Introduction}

Rivers prone to channel migration may be spanned by static structures and paralleled by fixed highway alignments and other appurtenances. Channel migration (alluvial river meander planform deformation) is a major consideration in designing bridge crossings and other transportation facilities in affected areas; it causes the channel alignment and approach conditions present during construction to deteriorate as the upstream channel location changes. Channel migration can result in the following: (a) excess bridge pier and abutment scour, (b) threats to bridge approaches and other highway infrastructure, (c) worsened debris problems, and (d) obstructed conveyance through bridge openings.

Channel migration includes lateral channel shift (expressed in terms of distance moved perpendicular to the channel center line, per year) and downvalley migration (expressed in distance moved along the valley, per year). Engineers are concerned about predicting channel migration as it moves through the bridge elements (piers and abutments) or endangers other highway infrastructure during design life. 
Geomorphologists may view channel stability from the perspective of hundreds or thousands of years. For highway engineering purposes, however, a stream channel can be considered unstable if the rate or magnitude of change is such that the planning, location, design, or maintenance considerations for a highway crossing are significantly affected during the life of the facility. The kinds of changes that are of concern are: (1) lateral bank erosion; (2) aggradation or degradation of the streambed; (3) short-term fluctuations in streambed elevation (scour and fill); and (4) avulsion. This research is concerned specifically with only lateral channel instability (including down valley migration) resulting from meander migration.

\section{Project Objective}

The objective of Research Project 24-16 is to develop a practical methodology to predict the rate and extent of lateral and down valley channel migration in proximity to transportation facilities. The methodology should enable practicing engineers to locate and design new bridges, highway facilities, or other structures, accommodate for anticipated channel migration, evaluate the risk to existing facilities, and if necessary, determine the need for and design countermeasures against the effects of channel migration. A prediction of channel migration could also be used to alert bridge inspection personnel to the potential for channel change that could affect the safety of a bridge. In addition, this methodology could be applied to channel restoration and stabilization efforts.

\section{Research Approach}

The fluvial processes involved in predicting meander migration are very complicated and the variables of importance are difficult to isolate. The major factors affecting alluvial stream channel forms are:

- $\quad$ stream discharge (magnitude and duration), temperature, and viscosity

- sediment load, including types and caliber of sediments

- longitudinal valley slope

- bank and bed resistance to erosion

- vegetation

- geology, including bedrock outcrops, clay plugs, and changes of valley slope

- human activity

In an analysis of flow in alluvial rivers, the flow field is further complicated by constantly changing discharge. Significant variables are, therefore, quite difficult to relate mathematically. It is often necessary to list measurable or computable variables, which effectively describe the processes occurring, and then to reduce the list by making simplifying assumptions and examining relative magnitudes of variables. This means that it is necessary to strive toward an acceptable balance between accuracy and limitations posed by data needs and analytical complexity.

Many laboratory and field studies have been carried out in an attempt to determine the variables controlling river response. To the present time, the problem has been more amenable to an empirical solution than an analytical one. Computer solutions to complex hydraulic problems 
have extended the range of fluvial process problems that can be solved analytically, but simplifying assumptions are still required. While the mathematical complexity of the analytical solution may be justified for research purposes, empirical approaches may produce results of greater utility to practicing engineers. After careful review of empirical and deterministic (physical process mathematical modeling) approaches to predicting meander migration, it was concluded that empirical approaches are more likely than deterministic approaches to yield a practical methodology that will be useful to practicing engineers.

The approach consists of the following tasks, many of which have already been completed:

- Conduct a complete and thorough literature review on meander migration.

- Access and evaluate a number of relatively complete existing data sets.

- Enhance existing data sets by acquiring recent aerial photography at selected study sites and obtain data on hydrologic, hydraulic and sediment characteristics.

- Analyze the enhanced data sets with photogrammetric comparisons.

- Develop a screening procedure to identify stable meandering reaches.

- Develop a classification system for river/meander types for stratification of the database.

- Develop a stand-alone Handbook for map/aerial photograph comparison techniques for measuring and predicting meander migration supplemented with regression analysis results.

- Compile and archive a database on CD-ROM that contains all acquired meander site data.

- Conduct necessary internal and external testing and evaluation and revise as necessary.

- Develop a detailed plan and recommendations for incorporating the results of this research into ongoing FHWA/National Highway Institute technology transfer programs.

\section{Procedure for Developing the Methodology to Predict Meander Migration}

The following six steps are necessary to achieve the goals of NCHRP Project 24-16:

(1) Assemble Final Data Set. In order to develop a methodology for predicting meander migration that can be used by bridge engineers and inspectors as well as other users, it was necessary to obtain data on numerous meandering rivers having a wide range of morphologies throughout the United States. The necessary data typically includes channel cross sections, channel planform, bed and bank material characteristics, vegetation, discharge data, sediment loads, floodplain characteristics, geology, and watershed characteristics. The data for each site was assembled and compiled into Microsoft Excel workbooks containing spreadsheets designated for each bend.

Existing data was collected from a variety of sources and researchers. The primary data set upon which much of this project is based comes from work conducted by Dr. James Brice of the U.S. Geological Survey. The Brice data set consists of morphometric data (Brice, 1982) as well as aerial photos, maps, and historic bankline tracings for 805 bends at 82 sites on 59 rivers. Under a research project at Johns Hopkins University, the data set was inventoried and additional data was derived for 133 of the Brice sites by Cherry et al. (1996). Additional survey and sediment data was collected for the Brice sites by field personnel from WES, the USGS, and the 
University of Nottingham, UK in 1999. Eight additional data sets, some with historic banklines or channel position atlases, covering 646 bends at 57 sites on 28 rivers were acquired from other sources.

Attempts were made to acquire appropriate historic aerial photography from various agencies for the data sets that had no historic bankline comparisons. Aerial photography from the 1990s and topographic maps were acquired for all the data sets. Updated discharge data was also obtained for each of the sites used in this project.

(2) Screen and Classify River and Meander Types. According to Brice (1982), it should be easy to identify stable meanders by their width characteristics. A simple stratification of meanders would be of value to the bridge engineer as a screening procedure, allowing identification of meanders that are very stable. Rather than developing regional relationships, a geomorphic classification was developed during this step to lead the user of the methodology to a suitable procedure for a particular river or meander type. A classification scheme modified from the channel pattern classification originally developed by Brice (1975) is presented in Figure 1 as an approach for both screening and classification. It is likely that the most common river types (or meander modes) encountered by DOTs in the field will be addressed by this classification.

(3) Measure Meander Morphology. In order to relate a meander to rate and type of change and to correlate its behavior with other variables, it is necessary to describe the meander quantitatively. Numerous investigators have done this by measuring amplitude, wavelength, radius of curvature, sinuosity, width and depth of the channel, width-depth ratio, and ratio of centerline radius of curvature to width. Following selection of meanders or sets of meanders for study, the maps and aerial photographs were compared in order to determine the rate of migration or change for each meander or segments of meanders.

(4) Collect Data on Controlling Variables. Each meander will be affected by its location and by the controlling variables that act upon it. This study assembled data on the character of the valley (slope, alluvial variability, bedrock controls), hydrology, and sediment type. Sediment type in the bed and banks of an alluvial river reflects the type of sediment load moved through the channel. Hydrologic data was obtained from nearby gaging stations. Channel dimensions and valley slope were obtained from topographic maps and aerial photographs. These data plus data on bed and bank sediments were obtained from various sources. Schumm (1960) concluded from his studies of Great Plains and Australian streams that width-depth ratio and sinuosity are determined by the type of sediment load moved through a channel. Although sediment loads will not be measured, width-depth ratio can be used as a surrogate for sediment load data.

(5) Develop Methodology. Based upon these steps, a predictive methodology has been developed for the highway engineer. Meander change or lack of change can be determined by comparing maps and aerial photographs of different dates. Because comparative aerial photography or maps are generally available, this may represent the most reliable predictor of meander migration for a specific site. A methodology and guidelines will be provided for comparison techniques ranging from the use of simple overlays to GIS techniques that can be implemented with the hardware and software normally available to a state highway agency. The 
predicted meander change is then compared with a frequency distribution of measured rates from the data set to assess the reasonableness of the prediction.

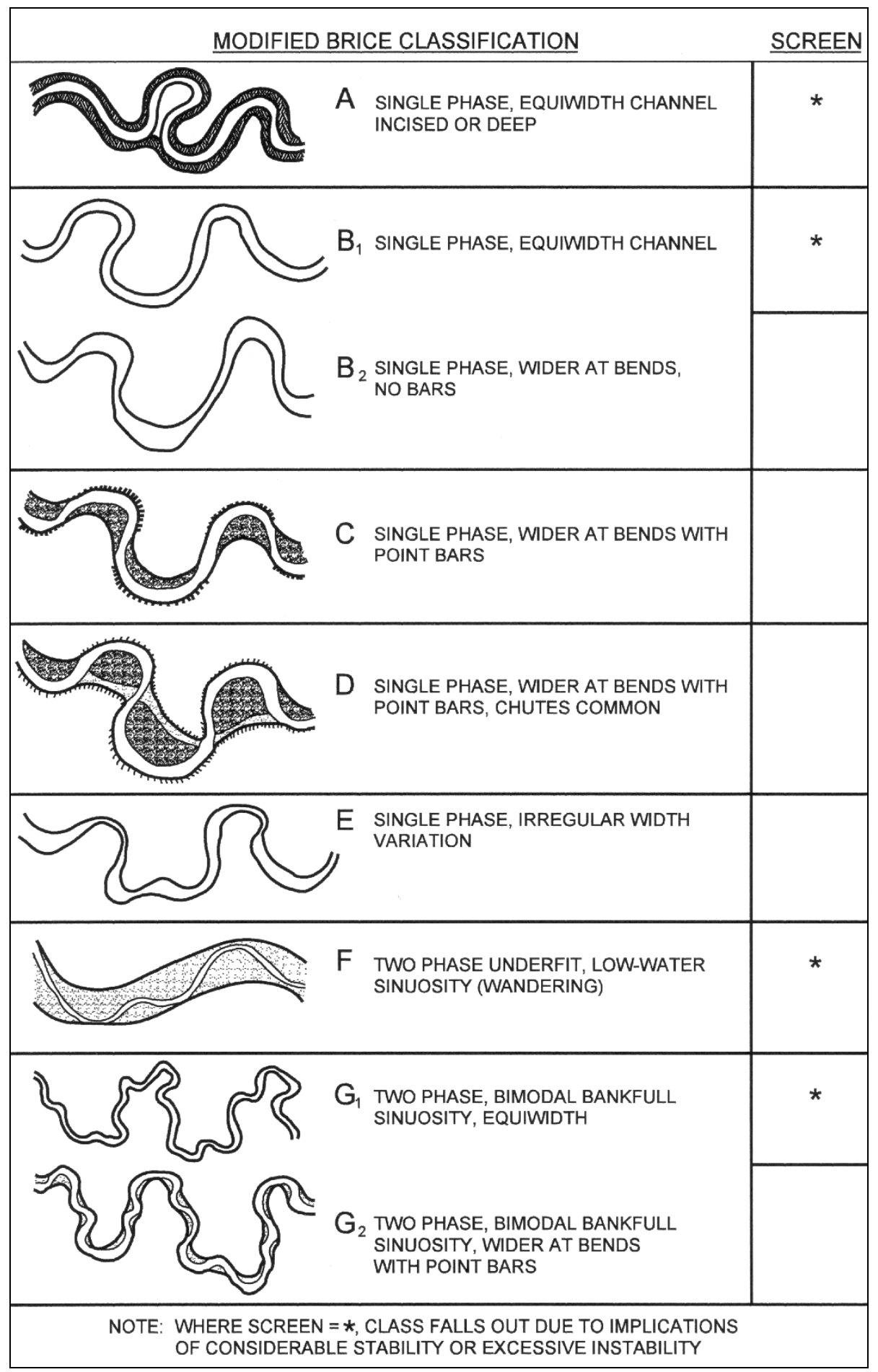

Figure 1. Modified Brice Classification of meandering rivers. 


\section{Measuring Meander Migration}

Before predictive tools for channel migration can be developed, one must be able to measure and describe channel migration. A standard approach for use in analyzing data sets must be developed and this approach should be adhered to for all subsequent measurements.

Bend migration can be reasonably described by four modes of movement (Figure 2). Extension is across-valley migration and is easily measured at the center of the bend radius $\left(\mathrm{R}_{\mathrm{c}}\right)$. Similarly, translation is down-valley migration and is also measured at the center of the bend radius. Expansion (or contraction) increases (or decreases) bendway radius. Rotation is a change in the orientation of the bendway with respect to the valley alignment.

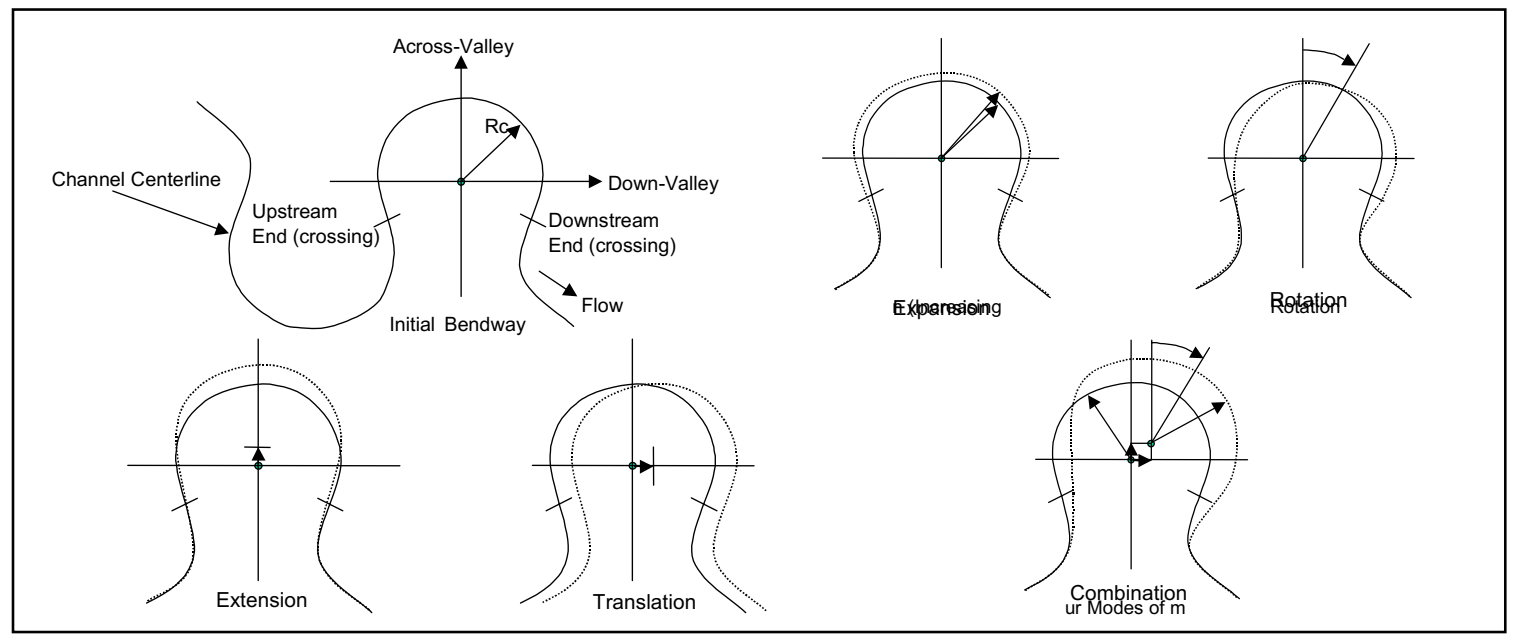

Figure 2. Measuring meander migration.

A change in any of these four modes of movement results in a change in the location of the outer bankline. Combinations of these modes of movement would result in a wide variety of bendway shapes through time. To apply this approach one must identify a valley orientation, locate the radial center of the bend, and measure the bendway radius and the orientation of the bendway with respect to the valley. If this is performed for consecutive aerial photos, rates of change in each of the modes of movement can be computed. This type of geometric information is needed to graphically depict channel migration of individual bends.

Predicting four modes of movement is a significant task for every bend of interest (Figure 2). However, actual bend migration is even more complex. One part of the bend may be expanding faster or translating down-valley faster than another. This would result in changes in bend symmetry. The above approach assumes fairly symmetrical bends. As a concession to practicality one must limit the number of modes of movement to the fewest possible and even four modes may be too complex to be practical. Although eliminating rotation is consistent with the project description, rotation will be accounted for since it is the vector representation of the combination of translation and extension. Expansion (a change in $R_{c}$ ) will be included, if 
possible, as it could have a major impact on the location of the outer bank and because rates of migration appear to be correlated to $\mathrm{R}_{\mathrm{c}} / \mathrm{W}$ (bend radius of curvature/width).

A GIS measurement tool to obtain the necessary data for both photogrammetric and regression analyses was developed for this project. The methodology for prediction of meander migration will concentrate on three modes of migration (extension, translation, and expansion - see Figure 2). If movement in these three modes can be predicted, the primary threats to a bridge or highway facility will be established. The GIS measurement tool has the capability to predict (extrapolate) meander migration at a given bend where the necessary sequential aerial photography or mapping is available.

\section{Aerial Photo and Map Comparison Handbook}

The principal product of this research will be an Aerial Photo and Map Comparison Handbook. As a minimum, the Handbook will cover the following topics:

- Screening and classification of meander sites

- Sources of mapping and aerial photographic data

- Basic principles and theory of aerial photograph comparison

- Simple overlay techniques

- GIS or computer supported techniques

- GIS based measurement and extrapolation techniques

- Sources of error and limitations

- Illustrated examples and applications

- Supplementing comparison analysis with regression results

While the final report for NCHRP 24-16 will provide a complete summary of the findings, recommendations, and implementation plan resulting from the project, the Handbook will provide the specific techniques and guidance to apply those results. The Handbook will also cover the screening and classification techniques (as a first step in any meander migration analysis) and the application of the results of the project regression analyses (as a check on the results of the photo/map comparison or as an analysis methodology where time-sequenced photography or mapping is not available). Finally, the Handbook will include a detailed description of the GIS meander migration prediction tool which will be compatible with the most recent version of ArcView.

\section{Anticipated Research Results}

A major task of this research is the development of aerial photograph comparison techniques and the GIS meander migration prediction tool that will provide an accurate means of predicting meander migration. As an example, aerial photograph comparison techniques and the GIS meander migration prediction tool were used in a preliminary attempt to predict meander migration on the White River in Indiana. Aerial photographs from 1937 and 1966 were acquired for a reach of the river, the banklines were delineated on each set of photographs, and the banklines were registered for comparison. Using the GIS meander migration prediction tool, the bankline position for 1995 was estimated. 
Figure 3 shows the actual 1937 bankline position of seven meander bends and the 1995 bankline positions of the bends predicted by the GIS meander migration prediction tool superposed on the 1966 aerial photograph. The 1995 bankline positions of the bends predicted by the GIS meander migration prediction tool were then overlain on the 1995 photograph obtained for this reach. Figure 4 shows the predicted 1995 bankline position superposed on the 1995 aerial photograph of the river.

A comparison of the actual bankline locations with the predicted bankline positions reveals that the GIS meander migration prediction tool can predict meander migration with relatively good accuracy. As seen in Figure 4, the 1995 bankline positions of Bends 3 and 4 and the cutoff at Bend 5 were accurately predicted. The unexpected and anomalous bankline positions can be accounted for by a man-made cutoff (Bends 1 and 2), a natural cutoff (Bends 5, 6 and 7), and, possibly, bank protection (Bends 3 and 5) prior to 1995. The man-made cutoff of Bend 1 may have been in response to the major threat posed by meander migration to a levee nearby. The cutoff has also caused Bend 2 to become distorted compared to the predicted shape. The cutoff of Bend 5 has resulted in the distortion of Bend 5 and abandonment of Bends 6 and 7 . The migration of the outer bank along the downstream limb of Bend 3 and at the apex of Bend 5 has been partially halted by apparent bank protection. It is quite likely that the bankline positions of Bends 1 and 2 as well as the revetted portions of Bends 3 and 4 would have closely matched the predicted positions if not for man's influence.

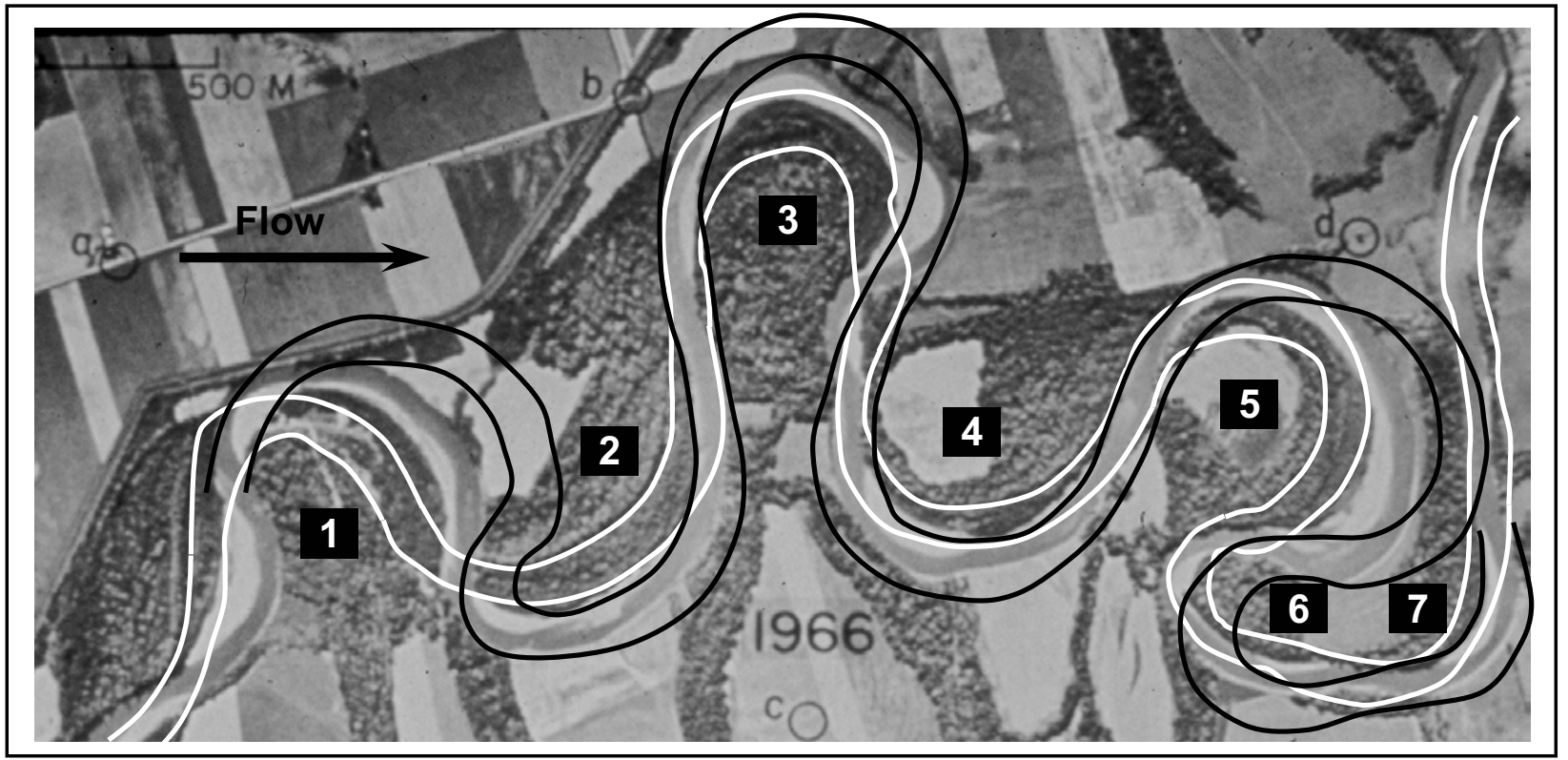

Figure 3. Aerial photo of the White River in 1966 showing the actual 1937 banklines (white) and the 1995 bankline positions (black) predicted by the GIS meander migration prediction tool. 


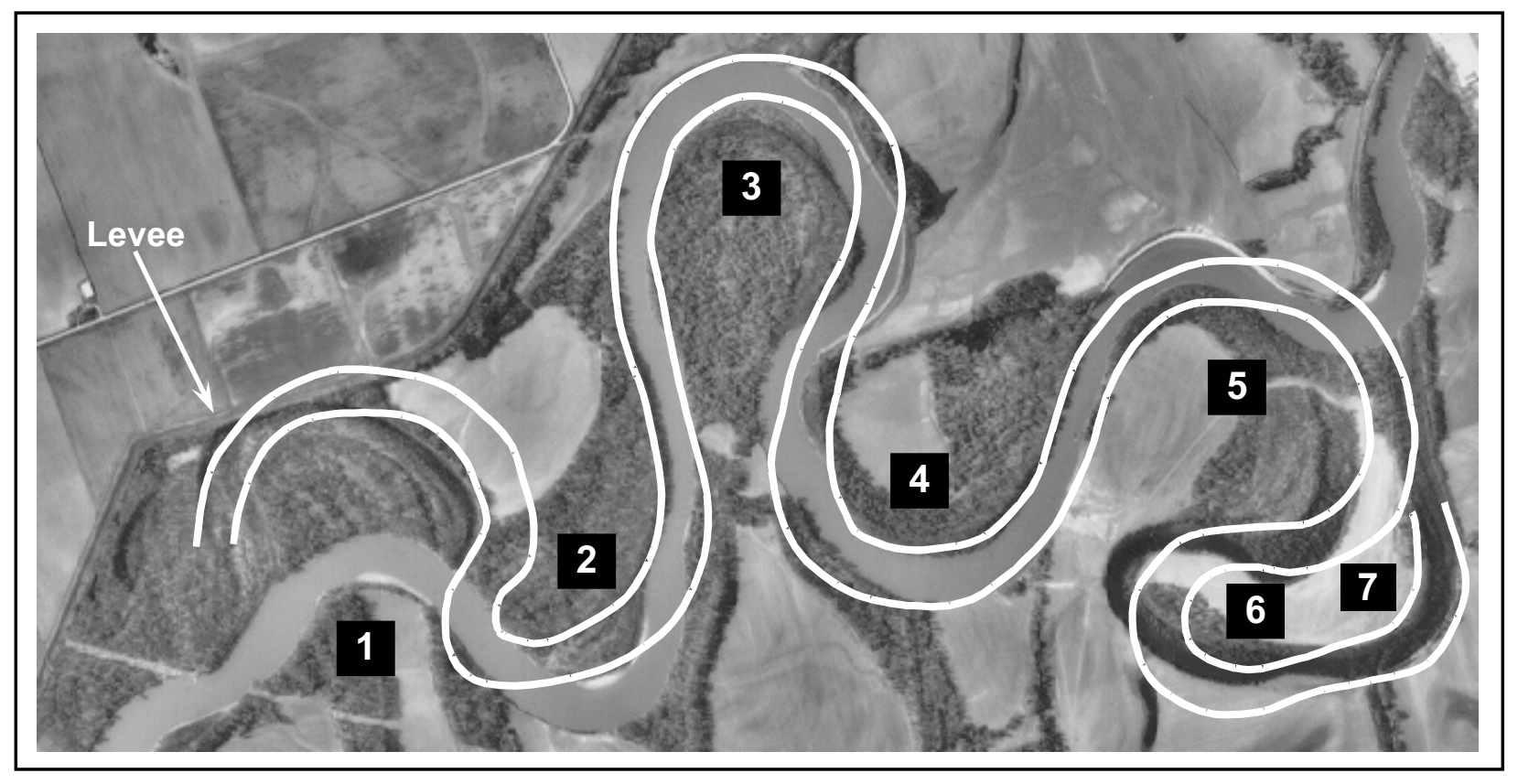

Figure 4. Aerial photograph of the White River in 1995 showing the bankline positions predicted using the GIS meander migration prediction tool.

\section{Summary}

A practical methodology to predict the rate and extent of channel migration at highway bridges could help reduce the cost of design, repair, rehabilitation and countermeasures for lateral channel instability. A screening procedure to identify stable meandering stream reaches would ensure that engineering and inspection resources are not allocated to locations where there is little probability of a problem developing.

The analytical products of this research, map/aerial photograph comparison techniques, and guidelines to predict channel migration in proximity to transportation facilities, will provide a practical quantitative methodology that will enable informed decision making at all levels. The methodology will be useful in reconnaissance, design, rehabilitation, maintenance and inspection of highway facilities, particularly if it is packaged to facilitate ease of application. The end result will be a more efficient use of highway resources and a reduction in costs associated with the impacts of channel migration on highway facilities.

The archived database will include all meander site data acquired for this study. With the archived data set, future researchers will have a readily accessible database in a very useable format for a variety of studies. These studies could include additional empirical analyses and more complex regressions based on the archived data. Additional data could be added to supplement or complement the database. As deterministic modeling code improves over the next decade, this archived data will facilitate calibration and verification of physical-process models of river meandering, providing additional tools beyond the empirical techniques of this research for the highway hydraulic engineer. 
It is anticipated that this project will be completed by mid-2003. Following the completion of the project, a final report detailing the methodology, the Aerial Photo and Map Comparison Handbook, and the archived database will be copyrighted and published.

\section{References}

Brice, J.C., 1975. Air Photo Interpretation of the Form and Behavior of Alluvial Rivers, Final report to the U.S. Army Research Office, Durham, North Carolina.

Brice, J.C., 1982. Stream Channel Stability Assessment, Report No. FHWA/RD/82/021, U.S. Department of Transportation Office of Research and Development, Washington, D.C., 42 p.

Cherry, D.S., Wilcock, P.R., and Wolman, M.G., 1996. Evaluation of Methods for Forecasting Planform Change and Bankline Migration in Flood-Control Channels, Johns Hopkins University, Prepared for: U.S. Army Engineer Waterways Experiment Station, Vicksburg, MS.

Schumm, S.A., 1960. The Shape of Alluvial Channels in Relation to Sediment Type, USGS Prof. Paper 352-B, pp. 17-30.

Schumm, S.A., 1977. The Fluvial System, John Wiley, N.Y., 338 p. 